\title{
Microbiome in Parturition and Preterm Birth
}

\author{
Indira U. Mysorekar, $\mathrm{PhD}^{1,2}$ Bin Cao, $\mathrm{PhD}^{1}$ \\ ${ }^{1}$ Department of Obstetrics and Gynecology \\ ${ }^{2}$ Department of Pathology and Immunology, Washington University \\ School of Medicine, St. Louis, Missouri \\ Semin Reprod Med 2014;32:50-55
}

\begin{abstract}
Address for correspondence Indira U. Mysorekar, PhD, Department of Obstetrics and Gynecology, Department of Pathology and Immunology, Washington University School of Medicine, 660 S. Euclid Avenue, St. Louis, MO 63110 (e-mail: indira@wustl.edu).
\end{abstract}

\begin{abstract}
Keywords

- pregnancy

- microbiome

- preterm birth

- parturition

- bacteria

Preterm parturition is a one of the most significant global maternal-child health problem. In recent years, there has been an explosion in reports on a role for microbiomes (i.e., a microbial biomass) on a plethora of physiologic and pathologic human conditions. This review aims to describe our current understanding of the microbiome and its impact on parturition, with particular emphasis on preterm birth. We will focus on the roles of vaginal and oral mucosal microbiomes in premature parturition and describe the state-of-the-art methodologies used in microbiome studies. Next, we will present new studies on a potential microbiome in the placenta and how it may affect pregnancy outcomes. Finally, we will propose that host genetic factors can perturb the normal "pregnancy microbiome" and trigger adverse pregnancy outcomes.
\end{abstract}

\section{Preterm Birth and Associated Morbidity and Mortality}

Preterm birth (PTB), defined as a live birth between 20 and 37 weeks of gestation, is a significant public health concern, affecting $12.7 \%$ of all births in the United States. PTB is a leading cause of perinatal morbidity and mortality in both developed and developing countries ${ }^{1,2} ; 27 \%$ of neonatal deaths are primarily attributable to PTB, and an additional $36 \%$ of neonatal deaths secondary to opportunistic infections (e.g., sepsis, pneumonia) are attributable to prematurity. Of those infants that survive, PTB is an independent risk factor for motor (cerebral palsy) and sensory (retinopathy and neuropathy) deficits, learning disabilities, and respiratory disorders (bronchopulmonary dysplasia). In fact, nearly $50 \%$ of preterm babies suffer from long-term neurologic sequelae. ${ }^{3}$ In addition to the global PTB, rate of prematurity is the astounding financial and social burden on the affected families. PTB-associated costs have been estimated in 2005 to exceed $\$ 26$ billion. $^{4}$

PTB-associated morbidity and mortality is tightly linked to the gestational age of the fetus. Therefore, PTBs are classified into extremely preterm (more than 20 weeks but fewer than 28 weeks of gestation), very preterm ( 28 weeks through 32 weeks), and moderate-to-late preterm (more than 32 weeks but less than 37 weeks). Over the past 25 years, the rate of PTB in the United States has increased by $36 \%$, and most of the increase has been in moderate-to-late PTBs. Increasing maternal age, rising rates of multiple gestations due to the use of assisted reproductive technologies, and a concomitant increase in indicated PTBs are major contributing factors driving this increase. ${ }^{5}$

PTB causes are generally grouped into the following categories: $30 \%$ are associated with preterm premature rupture of membranes, 45 to $50 \%$ are idiopathic, and 15 to $20 \%$ are medically indicated. ${ }^{6}$ However, the underlying etiologies (e. g., genetic factors, socioeconomic factors, or environmental factors) and mechanisms which may trigger various PTB subtypes remain largely unknown. Furthermore, to date, clinical interventions to reduce PTB have focused largely on specific risk factors, rather than on molecular-cellular etiology, and have arguably had less than optimal impact on elucidating PTB mechanisms. ${ }^{7}$

Because PTB is currently the most significant problem in maternal-fetal health, it is of the greatest importance to determine its causes, which will allow the field to develop novel methods of prevention and treatment. This review will focus on microbial (bacterial) etiologies for PTB.
Issue Theme The Microbiome and Reproduction; Guest Editors, James H. Segars, MD, and Kjersti M. Aagaard, $\mathrm{MD}, \mathrm{PhD}$
Copyright @ 2014 by Thieme Medical Publishers, Inc., 333 Seventh Avenue, New York, NY 10001, USA. Tel: +1(212) 584-4662.
DOI http://dx.doi.org/ 10.1055/s-0033-1361830. ISSN 1526-8004. 


\section{Infection and Preterm Birth Are Strongly Linked}

Infection is one of the most consistently identified risk factors for PTB. Intrauterine infection contributes to at least $25 \%$ of PTBs. Predisposing factors for infection-related PTB are diverse, including subclinical intrauterine infections, ${ }^{8}$ intra-amniotic infections, ${ }^{9,10}$ and pyelonephritis. ${ }^{11}$ Eleven to $80 \%$ of PTBs can be accompanied by intra-amniotic bacterial colonization. ${ }^{12,13}$ Further, experimental evidence for an unequivocal association between infection and PTB includes data that antibiotic treatment of ascending intrauterine infections can prevent PTB in experimental models of chorioamnionitis, treatment of asymptomatic bacteriuria prevents PTB, and systemic administration of microbial products to pregnant animals results in spontaneous preterm labor and PTB. ${ }^{14,15}$ PTB-causing infections have been postulated to begin in the reproductive or genitourinary tract, ascend upward toward the uterus, and possibly cross the placental barrier. Potential sites of infection in proximity to the fetus include the amniotic fluid, placenta, fetal membranes, and umbilical cord. ${ }^{16}$

Because the risk of PTB recurrence can reach as high as $48 \%,{ }^{17}$ identification of the etiologic infectious agents (both culturable and nonculturable organisms, known and unknown) is essential to better stratify recurrence estimates, provide targeted and efficacious interventions, and reduce the risk of PTB in subsequent pregnancies. The development of effective treatments will require identifying the relevant sites of infection, the pathogens involved, and the mechanisms by which pathogens induce pathological change during pregnancy.

\section{Infectious Organisms and Etiologies Associated with Preterm Birth}

A wide variety of bacterial species have been identified in PTBassociated infections; the most prevalent being Ureaplasma urealyticum, Mycoplasma hominis, Bacteroides spp., Gardnerella vaginalis, and Fusobacterium nucleatum. ${ }^{16,18}$ We refer the reader to a recent review ${ }^{19}$ for a detailed description of the bacterial species that have been associated with PTB. ${ }^{20,21}$ It has been suggested that the majority of these bacterial species exhibit typically low virulent properties. However, once inside the uterine environment, they are capable of stimulating production and release of proinflammatory cytokines, prostaglandins, and metalloproteases together with myeloid cell influx. These events can trigger cervical ripening and shortening, membrane weakening and rupture, uterine contractions, and PTB $^{16}$ In addition, the presence of organisms in the amniotic cavity may elicit a fetal inflammatory response, which predisposes preterm neonates to short- and longterm consequences, such as neonatal sepsis, bronchopulmonary dysplasia, and cerebral palsy.

\section{Relevance of the Human Microbiome in Pregnancy}

Although microbes have historically been viewed only as pathogens, many microorganisms live in a symbiotic rela- tionship with the host and protect the host from harmful pathogens. ${ }^{22-24}$ In fact, the microbial genome exceeds the human genome by a 100 -fold, and adult human cells are outnumbered $10: 1$ by microbial cells. ${ }^{25}$ The human genome interacts with, and has evolved alongside, the genomes of 10 to 100 trillion bacterial cells. ${ }^{26}$ To understand this coevolution and begin to understand how bacterial cells we play host to, govern human health and disease, it is essential to understand the bacterial genomic diversity and composition at various mucosal sites in the human body. Accordingly, the National Institutes of Health launched the 5-year Human Microbiome Project (HMP) in 2007 with the ambitious goal of understanding human-microbe and microbe-microbe interactions in healthy adults. ${ }^{27}$ These efforts are producing comprehensive genomic characterization of the healthy adult human microbiota, which can be used as a comparison for diseases states. With the advent of next-generation sequencing and whole genome shotgun sequencing, the field of metagenomics has been evolving rapidly. Traditional sequencing methods, such as Sanger sequencing, only allowed analysis of a few samples at a time, and enabled sampling of only the most predominant species present. In the past decade, however, next-generation sequencing techniques have made it possible to obtain a comprehensive analysis of the species present within a given body site by enabling the simultaneous reading of tens to even hundreds of thousands of sequences. It is now possible to obtain a detailed catalog of the bacterial species present in a given human sample. Furthermore, metagenomics has facilitated the sequencing and identification of nonculturable species thus providing a wealth of information into microbial etiologies for several disease conditions. Finally, given the increasing sequencing capacity at diminished cost, our ability to acquire and analyze complex metagenomic data will undoubtedly continue to increase.

With the ever-increasing quantity of genomic data, analytic methods are also rapidly evolving (for a thorough description of the methods, we refer the reader to an excellent recent review $^{28}$ ). For example, it is now possible to generate a microbiome gene catalog. Functional genomic information regarding presence and abundance of microbial pathways can be determined with relative ease. Meta-RNA sequencing can be used to map gene expression data to determine bacterial gene expression profiles relative to the total gene pool of the human microbiome. Finally, on the host side, host genomic sequences can also be analyzed to obtain information on genomic variants, including single nucleotide polymorphism (SNPs) and copy number variations. This could, for example, allow investigations into how host genomic variants associated with PTB may affect microbiome composition.

\section{Defining the Microbiome of Preterm Birth}

\section{Vaginal Microbiome, Bacterial Vaginosis, and Preterm Birth}

There are currently no published next-generation sequencing-based analyses of a microbiome associated with PTB. In the past decade, however, there have been several reports 
describing utero-invasive bacteria using polymerase chain reaction (PCR) or culture-based approaches. For example, Ureaplasma cultures are positively associated with PTB. ${ }^{29}$ Culture-based analyses of chorioamniotic membranes most commonly detected Ureaplasma and G. vaginalis, whereas Mycoplasma were most commonly detected in amniotic fluids, using culture or PCR methods. ${ }^{30,31}$ Additional bacterial species associated with amniotic fluids include Leptotrichia, Sneathia, and Bergeyella. ${ }^{30,32}$

Recent studies have also started to flesh out the complexity and diversity of the vaginal microbiome in the nonpregnant female and in pregnant women through the course of pregnancy. ${ }^{28}$ The healthy vagina is predominantly colonized by lactobacilli, which can prevent colonization by other species and are thought to maintain a healthy, stable low $\mathrm{pH}$ environment through the production of lactic acid and hydrogen peroxide. ${ }^{33}$ The vaginal microbiome of reproductive-age women reveals tremendous variance in the dominance of Lactobacillus species. For example, sequencing of vaginal swabs from 200 randomly selected subjects revealed that more than half exhibited significant diversity in the composition of their vaginal microbiomes, considerable variability in vaginal $\mathrm{pH}$, and that differences in $\mathrm{pH}$ and bacterial composition were associated with ethnicity. ${ }^{34}$ Prominent changes in the vaginal flora that result in $\mathrm{pH}$ variation are associated with increased risk of PTB. ${ }^{35}$ Furthermore, Hyman and colleagues recently showed that the overall diversity of the vaginal microbiome correlated positively with PTB with race and ethnicity and sampling sites being key variables.

Culture-based methods have also identified bacterial vaginosis ( $\mathrm{BV}$, a condition in which the normal vaginal flora of lactobacilli are replaced by other low- and high-grade pathogens)-associated species including G. vaginalis, Prevotella bivia, and Peptostreptococcus. ${ }^{30,36} \mathrm{BV}$ has been implicated as a risk factor for PTB and associated morbidities. $^{37-41}$ The racial disparity in rates of PTB is mirrored in rates of BV: $11 \%$ of Caucasian women deliver preterm and 10 to $20 \%$ of Caucasians have BV, $18 \%$ of African American women deliver preterm and 30 to $50 \%$ of African American women have BV. ${ }^{21}$ Thus, BV doubles the relative risk for PTB in the Caucasian population, but this disorder more than triples the risk in African American women. ${ }^{42}$ In fact, BV may account for as much as $30 \%$ of the racial gap in rates of PTB. ${ }^{43}$ During BV, the numbers of lactobacilli drop and the numbers of anaerobes increase dramatically, resulting in a tremendous increase in bacterial burden and species diversity. Studies have analyzed the roles of Atopobium vaginae, Mycoplasma hominis, and G. vaginalis among other species to establish an association between bacterial colonization and preterm labor, but as of yet, there has been no unequivocally clear role determined for any single species in PTB. ${ }^{44,45}$

HMPs dedicated to the vaginal microbiome are now revealing the full spectrum of species that are associated with $\mathrm{BV} .{ }^{46}$ Understanding the balance between vaginal colonization with lactobacilli and BV-associated organisms will enable more targeted therapeutic interventions.

\section{Oral Microbiome and Preterm Birth}

Intrauterine infections are thought to predominantly originate from pathogens in the vaginal tract that ascend into the sterile uterus. However, improved genome sequencing efforts have determined that in fact many utero-invasive bacteria do not belong to the vaginal microflora. Instead, several studies have elucidated that intrauterine infections may be caused by bacterial species that are components of the commensal oral flora, such as F. nucleatum and Bergeyella, Eikenella, and Capnocytophaga spp. ${ }^{18,32,47}$ Oral flora comprises more than 700 microbial taxa ${ }^{48,49}$ and thus may serve as a potential reservoir for infection. These findings suggest a hematogenous route of pathogenic transmission. ${ }^{50}$

The link between oral flora, periodontal disease, and PTB gained further attention after Offenbacher et al observed a possible association between periodontal disease and PTBs in a case-control study. ${ }^{51}$ Periodontal diseases are among the most common chronic infections, affecting up to $50 \%$ of humans. During periodontal infection, oral bacterial titers increase dramatically, accompanied by inflammation and bleeding in the gingival tissue. These conditions lead to increased bacteremia, which enhances the opportunities for hematogenous transmission. Consistent with this idea, periodontal pathogens have been detected in placentas of women with preeclampsia ${ }^{52}$ and in the amniotic fluid of pregnant women with preterm labor. ${ }^{51,53,54}$ These findings have led to the proposal that periodontitis may represent a distant source of systemic inflammation in the mother. Alternatively, periodontitis may affect the placenta directly through the hematogenous translocation of periodontal pathogens. However, associative studies have produced different results in different population groups, and no conclusive evidence has yet demonstrated that preventive periodontal care can reduce the risk of PTB. ${ }^{55}$

One important question is to determine the proportion of the oral microbiome that is capable of oral-uterus transmission. Given that the majority of the bacteria in the oral cavity are uncultivated, it is very likely that the involvement of oral bacteria in intrauterine infection has been significantly underestimated. ${ }^{32}$ As a result, clinical evidence linking oral bacteria to PTB is incomplete. State-of-the-art next-generation sequencing and metagenomic analyses are warranted to provide comprehensive knowledge of the diversity of oral bacterial involved in PTB.

\section{Intracellular Microbes and Placenta: Is There a Placental Microbiome?}

Among the important contributors to PTB are microorganisms (both pathogenic and perturbed microbiome communities) that we have already discussed and genetic variants that modify and mediate host susceptibility to infection. The role of maternal genomic variation in mediating susceptibility to spontaneous PTB has been extensively studied, ${ }^{56-60}$ but studies imputing susceptibility loci and microbiome profiles to PTB are needed. These are likely essential steps in elucidating underlying mechanisms of spontaneous PTB.

Mammalian pregnancy is a state of immune tolerance maintained by multiple mechanisms. One major mechanism 
is via the major histocompatibility complex molecule human leukocyte antigen-G (HLA-G), which is expressed on extravillous trophoblast (EVT) cells, and modulates maternal natural killer cells. HLA proteins identify cells as "self" or "nonself" to the host immune system. Dysregulation of antigen recognition of the HLA system occurs in autoimmune disease, transplant organ rejection, or tumor growth, ${ }^{61}$ and polymorphisms in HLA-G have been linked to recurrent spontaneous abortion. ${ }^{62}$ Studies have found that amniotic fluid levels of HLA-G are significantly higher in pregnancies complicated by toxoplasmosis infection, with the highest levels found in pregnancies with transplacental transmis$\operatorname{sion}^{63}$ and correlated significantly with intra-amniotic infection. ${ }^{14}$ Levels of soluble HLA-G in the amniotic fluid have been shown to be elevated in patients with spontaneous preterm labor. ${ }^{64}$ Furthermore, recent studies have found increased maternal serum HLA class I antibodies to be associated with spontaneous PTB and fetal inflammatory responses, suggesting a component of maternal-antifetal rejection in the pathogenesis of РТВ. ${ }^{65,66}$ Maternal-fetal gene-environment interactions in terms of HLA-G expression may thus jointly contribute to pregnancy tolerance and PTB.

Recently, we showed that intracellular bacteria were present in the basal plate, the peripheral region of the placenta on the maternal side in contact with the uterine wall, of $27 \%$ of all placentas $(n=195)$ and $54 \%(p<0.05)$ of placentas from very PTBs. ${ }^{67}$ We found that these intracellular bacteria were present in the HLA-G positive EVTs (-Fig. 1), which are found exclusively in the basal plate. EVTs are the fetally derived and invade into the maternal basal plate, thus coming into contact with maternal stromal and immune cells. ${ }^{68,69}$

The presence of intracellular bacteria in a quarter of placental basal plates is noteworthy in terms of potential pathologic effect of basal plate colonization as a contributor to PTB. However, the bacterial type, functions, and host responses to the bacteria within cells in the basal plate are unknown, and may collectively determine the outcome

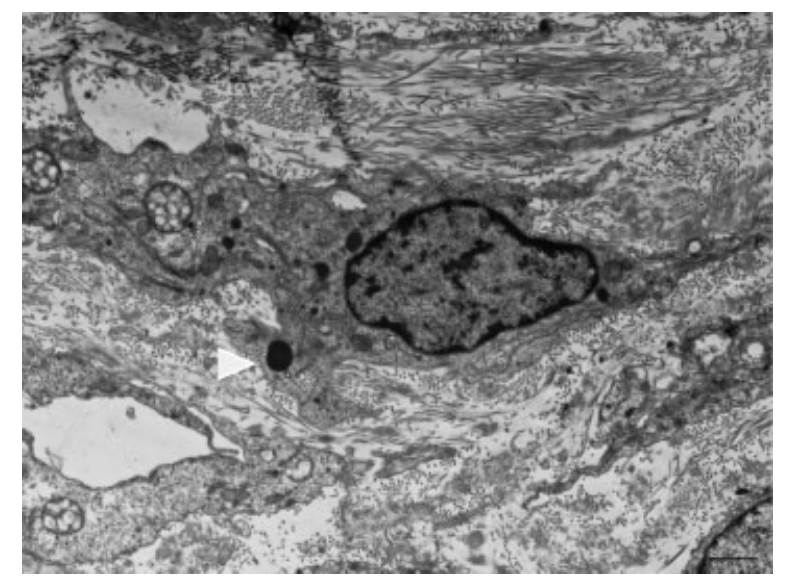

Figure 1 Transmission electron micrograph of bacteria (white arrowhead points to the electron dense single bacillus) within an extravillous trophoblast embedded within the basal plate from a term C-sectioned placenta from a woman with no clinical diagnosis of infection. Image $=\times 3,000$ magnification. Bar $=2 \mu \mathrm{m}$. from the presence of intracellular bacteria. The presence of bacteria in normal term deliveries, as well as the absence of bacteria in many cases of extreme prematurity, suggests that the phenotype of PTB is mediated not just by the presence or absence of bacteria, but likely by more complex relationships between the bacterial types, host tissue, and host responses. It is possible, for example, that certain microbes in the basal plate are truly commensal and exert no pathologic effect, whereas others microbes may activate the inflammatory cascade predisposing to PTB. The location of bacterial colonization in an immune privileged cell type and the association of HLA-G with PTB may well be a pivot balancing fetal tolerance with maternal immunity. Future investigations regarding the specific type and function of these microbes, and whether they constitute a placental microbiome are required to fully elucidate the normal or pathogenic relationship between host and microbes in the basal plate and indeed other regions of the placenta.

\section{Conclusions}

Several decades of research indicate that infection confers risk for PTB, and this risk is mediated by human host genetic susceptibility. Evidence from both human and animal models suggests that infectious etiologies for РТВ could originate in the lower genitourinary tract, but also that hematogenous transmission is an alternative route of infection. Furthermore, there is new evidence that microbes can reside in the placenta. The developing technological advances and analytical tools will provide unprecedented insights into both host and microbial effects on placental function and risk of PTB. To understand the deviation from normal pregnancy, studies must catalog the establishment of the "pregnancy microbiome" at different sites and throughout gestation. Such studies should focus on understanding the evolution of the pregnancy microbiome and the responsible maternal, environmental, and fetal factors. With current deep-sequencing technology, a well-characterized prospective study comparing pregnancy microbiomes in preterm and normal delivery would improve our understanding of microorganisms associated with PTB and possibly guide development of preventive and therapeutic interventions.

\section{Acknowledgments}

Dr. Mysorekar is supported by a Preventing Prematurity Initiative grant from the Burroughs Wellcome Fund and a Prematurity Research Initiative Investigator award from the March of Dimes. We thank Deborah Frank, PhD, for comments.

\section{References}

1 Goldenberg RL, Culhane JF, Iams JD, Romero R. Epidemiology and causes of preterm birth. Lancet 2008;371(9606):75-84

2 Liew G, Wang JJ, Mitchell P. Preterm birth, long-term survival, and fertility. JAMA 2008;300(2):167, author reply 167-168 
3 Iacovidou N, Varsami M, Syggellou A. Neonatal outcome of preterm delivery. Ann N Y Acad Sci 2010;1205:130-134

4 MacDorman MF, Munson ML, Kirmeyer S. Fetal and perinatal mortality, United States, 2004. Natl Vital Stat Rep 2007;56(3):1-19

5 Lawn JE, Gravett MG, Nunes TM, Rubens CE, Stanton C; GAPPS Review Group. Global report on preterm birth and stillbirth (1 of 7): definitions, description of the burden and opportunities to improve data. BMC Pregnancy Childbirth 2010;10(Suppl 1):S1

6 Beck S, Wojdyla D, Say L, et al. The worldwide incidence of preterm birth: a systematic review of maternal mortality and morbidity. Bull World Health Organ 2010;88(1):31-38

7 Goldenberg RL, Rouse DJ. Prevention of premature birth. N Engl J Med 1998;339(5):313-320

8 Gibbs RS, Romero R, Hillier SL, Eschenbach DA, Sweet RL. A review of premature birth and subclinical infection. Am J Obstet Gynecol 1992;166(5):1515-1528

9 Romero R, Sirtori M, Oyarzun E, et al. Infection and labor. V. Prevalence, microbiology, and clinical significance of intraamniotic infection in women with preterm labor and intact membranes. Am J Obstet Gynecol 1989;161(3):817-824

10 Romero R, Espinoza J, Rogers WT, et al. Proteomic analysis of amniotic fluid to identify women with preterm labor and intraamniotic inflammation/infection: the use of a novel computational method to analyze mass spectrometric profiling. J Matern Fetal Neonatal Med 2008;21(6):367-388

11 Schieve LA, Handler A, Hershow R, Persky V, Davis F. Urinary tract infection during pregnancy: its association with maternal morbidity and perinatal outcome. Am J Public Health 1994;84(3): 405-410

12 Watts DH, Krohn MA, Hillier SL, Eschenbach DA. The association of occult amniotic fluid infection with gestational age and neonatal outcome among women in preterm labor. Obstet Gynecol 1992; 79(3):351-357

13 DiGiulio DB, Romero R, Kusanovic JP, et al. Prevalence and diversity of microbes in the amniotic fluid, the fetal inflammatory response, and pregnancy outcome in women with preterm pre-labor rupture of membranes. Am J Reprod Immunol 2010;64(1):38-57

14 Romero R, Espinoza J, Gonçalves LF, Kusanovic JP, Friel LA, Nien JK. Inflammation in preterm and term labour and delivery. Semin Fetal Neonatal Med 2006;11(5):317-326

15 Romero R, Espinoza J, Kusanovic JP, et al. The preterm parturition syndrome. BJOG 2006;113(Suppl 3):17-42

16 Goldenberg RL, Hauth JC, Andrews WW. Intrauterine infection and preterm delivery. N Engl J Med 2000;342(20):1500-1507

17 Meis PJ, Klebanoff M, Thom E, et al; National Institute of Child Health and Human Development Maternal-Fetal Medicine Units Network. Prevention of recurrent preterm delivery by 17 alphahydroxyprogesterone caproate. N Engl J Med 2003;348(24): 2379-2385

18 Hill GB. Preterm birth: associations with genital and possibly oral microflora. Ann Periodontol 1998;3(1):222-232

19 Jefferson KK. The bacterial etiology of preterm birth. Adv Appl Microbiol 2012;80:1-22

20 Jones HE, Harris KA, Azizia M, et al. Differing prevalence and diversity of bacterial species in fetal membranes from very preterm and term labor. PLoS ONE 2009;4(12):e8205

21 Hyman RW, Fukushima M, Jiang H, et al. Diversity of the Vaginal Microbiome Correlates With Preterm Birth. Reprod Sci 2013; (May):28

22 Qin J, Li R, Raes J, et al; MetaHIT Consortium. A human gut microbial gene catalogue established by metagenomic sequencing. Nature 2010;464(7285):59-65

23 Costello EK, Lauber CL, Hamady M, Fierer N, Gordon JI, Knight R. Bacterial community variation in human body habitats across space and time. Science 2009;326(5960):1694-1697

24 Ley RE, Peterson DA, Gordon JI. Ecological and evolutionary forces shaping microbial diversity in the human intestine. Cell 2006; 124(4):837-848
25 Turnbaugh PJ, Ley RE, Hamady M, Fraser-Liggett CM, Knight R, Gordon JI. The human microbiome project. Nature 2007; 449(7164):804-810

26 Proctor LM. The Human Microbiome Project in 2011 and beyond. Cell Host Microbe 2011;10(4):287-291

27 Peterson J, Garges S, Giovanni M, et al; NIH HMP Working Group. The NIH Human Microbiome Project. Genome Res 2009;19(12): 2317-2323

28 Ganu RS, Ma J, Aagaard KM. The role of microbial communities in parturition: is there evidence of association with preterm birth and perinatal morbidity and mortality? Am J Perinatol 2013;30(8): 613-624

29 Gray DJ, Robinson HB, Malone J, Thomson RB Jr. Adverse outcome in pregnancy following amniotic fluid isolation of Ureaplasma urealyticum. Prenat Diagn 1992;12(2):111-117

30 DiGiulio DB, Gervasi M, Romero R, et al. Microbial invasion of the amniotic cavity in preeclampsia as assessed by cultivation and sequence-based methods. J Perinat Med 2010;38(5):503-513

31 Hillier SL, Martius J, Krohn M, Kiviat N, Holmes KK, Eschenbach DA. A case-control study of chorioamnionic infection and histologic chorioamnionitis in prematurity. N Engl J Med 1988;319(15):972-978

32 Han YW, Shen T, Chung P, Buhimschi IA, Buhimschi CS. Uncultivated bacteria as etiologic agents of intra-amniotic inflammation leading to preterm birth. J Clin Microbiol 2009;47(1):38-47

33 Tamrakar R, Yamada T, Furuta I, et al. Association between Lactobacillus species and bacterial vaginosis-related bacteria, and bacterial vaginosis scores in pregnant Japanese women. BMC Infect Dis 2007;7:128

34 Ravel J, Gajer P, Abdo Z, et al. Vaginal microbiome of reproductiveage women. Proc Natl Acad Sci U S A 2011;108(Suppl 1): 4680-4687

35 Sendag F, Kazandi M, Akercan F, Kazandi AC, Karadadas N, Sagol S. Vaginal fluid $\mathrm{pH}$, cervicovaginitis and cervical length in pregnancy. Clin Exp Obstet Gynecol 2010;37(2):127-130

36 Fichorova RN, Onderdonk AB, Yamamoto $\mathrm{H}$, et al. Maternal microbe-specific modulation of inflammatory response in extremely low-gestational-age newborns. mBio 2011;2(1):e00280-00210

37 Laxmi U, Agrawal S, Raghunandan C, Randhawa VS, Saili A. Association of bacterial vaginosis with adverse fetomaternal outcome in women with spontaneous preterm labor: a prospective cohort study. J Matern Fetal Neonatal Med 2012;25(1):64-67

38 Sanu O, Lamont RF. Periodontal disease and bacterial vaginosis as genetic and environmental markers for the risk of spontaneous preterm labor and preterm birth. J Matern Fetal Neonatal Med 2011;24(12):1476-1485

39 Mancuso MS, Figueroa D, Szychowski JM, Paden MM, Owen J. Midtrimester bacterial vaginosis and cervical length in women at risk for preterm birth. Am J Obstet Gynecol 2011;204(4): e341-345

40 Jones NM, Holzman C, Friderici KH, et al. Interplay of cytokine polymorphisms and bacterial vaginosis in the etiology of preterm delivery. J Reprod Immunol 2010;87(1-2):82-89

41 Gómez LM, Sammel MD, Appleby DH, et al. Evidence of a geneenvironment interaction that predisposes to spontaneous preterm birth: a role for asymptomatic bacterial vaginosis and DNA variants in genes that control the inflammatory response. Am J Obstet Gynecol 2010;202(4):e381-386

42 Sobel JD. What's new in bacterial vaginosis and trichomoniasis? Infect Dis Clin North Am 2005;19(2):387-406

43 Fiscella K. Racial disparities in preterm births. The role of urogenital infections. Public Health Rep 1996;111(2):104-113

44 Ferris MJ, Masztal A, Aldridge KE, Fortenberry JD, Fidel PL Jr, Martin DH. Association of Atopobium vaginae, a recently described metronidazole resistant anaerobe, with bacterial vaginosis. BMC Infect Dis 2004;4:5

45 Menard JP, Fenollar F, Henry M, Bretelle F, Raoult D. Molecular quantification of Gardnerella vaginalis and Atopobium vaginae loads to predict bacterial vaginosis. Clin Infect Dis 2008;47(1): 33-43 
46 Fettweis JM, Serrano MG, Sheth NU, et al; Vaginal Microbiome Consortium (additional members). Species-level classification of the vaginal microbiome. BMC Genomics 2012;13(Suppl 8):S17

47 Han YW, Ikegami A, Bissada NF, Herbst M, Redline RW, Ashmead GG. Transmission of an uncultivated Bergeyella strain from the oral cavity to amniotic fluid in a case of preterm birth. J Clin Microbiol 2006;44(4):1475-1483

48 Aas JA, Paster BJ, Stokes LN, Olsen I, Dewhirst FE. Defining the normal bacterial flora of the oral cavity. J Clin Microbiol 2005; 43(11):5721-5732

49 Paster BJ, Boches SK, Galvin JL, et al. Bacterial diversity in human subgingival plaque. J Bacteriol 2001;183(12):3770-3783

50 Fardini Y, Chung P, Dumm R, Joshi N, Han YW. Transmission of diverse oral bacteria to murine placenta: evidence for the oral microbiome as a potential source of intrauterine infection. Infect Immun 2010;78(4):1789-1796

51 Offenbacher S, Katz V, Fertik G, et al. Periodontal infection as a possible risk factor for preterm low birth weight. J Periodontol 1996;67(10, Suppl):1103-1113

52 Barak S, Oettinger-Barak O, Oettinger M, Machtei EE, Peled M, Ohel G. Common oral manifestations during pregnancy: a review. Obstet Gynecol Surv 2003;58(9):624-628

53 León R, Silva N, Ovalle A, et al. Detection of Porphyromonas gingivalis in the amniotic fluid in pregnant women with a diagnosis of threatened premature labor. J Periodontol 2007;78(7): 1249-1255

54 Gardella C, Riley DE, Hitti J, Agnew K, Krieger JN, Eschenbach D. Identification and sequencing of bacterial rDNAs in culture-negative amniotic fluid from women in premature labor. Am J Perinatol 2004;21(6):319-323

55 Wang X, Buhimschi CS, Temoin S, Bhandari V, Han YW, Buhimschi IA. Comparative microbial analysis of paired amniotic fluid and cord blood from pregnancies complicated by preterm birth and early-onset neonatal sepsis. PLoS ONE 2013;8(2):e56131

56 Bodamer OA, Mitterer G, Maurer W, Pollak A, Mueller MW, Schmidt WM. Evidence for an association between mannosebinding lectin 2 (MBL2) gene polymorphisms and pre-term birth. Genet Med 2006;8(8):518-524

57 Chaves JH, Babayan A, Bezerra CdeM, Linhares IM, Witkin SS. Maternal and neonatal interleukin-1 receptor antagonist genotype and pregnancy outcome in a population with a high rate of pre-term birth. Am J Reprod Immunol 2008;60(4):312-317
58 Murtha AP, Nieves A, Hauser ER, et al. Association of maternal IL-1 receptor antagonist intron 2 gene polymorphism and preterm birth. Am J Obstet Gynecol 2006;195(5):1249-1253

59 Rey G, Skowronek F, Alciaturi J, Alonso J, Bertoni B, Sapiro R. Toll receptor 4 Asp299Gly polymorphism and its association with preterm birth and premature rupture of membranes in a South American population. Mol Hum Reprod 2008;14(9):555-559

60 Yllmaz Y, Verdi H, Taneri A, et al. Maternal-fetal proinflammatory cytokine gene polymorphism and preterm birth. DNA Cell Biol 2012;31(1):92-97

61 Shiina T, Inoko H, Kulski JK. An update of the HLA genomic region, locus information and disease associations: 2004. Tissue Antigens 2004;64(6):631-649

62 Aldrich CL, Stephenson MD, Karrison T, et al. HLA-G genotypes and pregnancy outcome in couples with unexplained recurrent miscarriage. Mol Hum Reprod 2001;7(12):1167-1172

63 Robert-Gangneux F, Gangneux JP, Vu N, Jaillard S, Guiguen C, Amiot L. High level of soluble HLA-G in amniotic fluid is correlated with congenital transmission of Toxoplasma gondii. Clin Immunol 2011;138(2):129-134

64 Kusanovic JP, Romero R, Jodicke C, et al. Amniotic fluid soluble human leukocyte antigen-G in term and preterm parturition, and intra-amniotic infection/inflammation. J Matern Fetal Neonatal Med 2009;22(12):1151-1166

65 Lee J, Romero R, Chaiworapongsa T, et al. Characterization of the fetal blood transcriptome and proteome in maternal anti-fetal rejection: evidence of a distinct and novel type of human fetal systemic inflammatory response. Am J Reprod Immunol 2013; 70(4):265-284

66 Lee J, Romero R, Xu Y, et al. Detection of anti-HLA antibodies in maternal blood in the second trimester to identify patients at risk of antibody-mediated maternal anti-fetal rejection and spontaneous preterm delivery. Am J Reprod Immunol 2013;70(2): $162-175$

67 Stout MJ, Conlon B, Landeau M, et al. Identification of intracellular bacteria in the basal plate of the human placenta in term and preterm gestations. Am J Obstet Gynecol 2013;208(3): e221-227

68 Red-Horse K, Zhou Y, Genbacev O, et al. Trophoblast differentiation during embryo implantation and formation of the maternal-fetal interface. J Clin Invest 2004;114(6):744-754

69 Norwitz ER, Schust DJ, Fisher SJ. Implantation and the survival of early pregnancy. N Engl J Med 2001;345(19):1400-1408 